moon. Had we included admissions for self-injury and accidental poisoning, including smoke injury, the figures would have been 390 and 336. The mean number of selfpoisoning admissions, with standard deviation, on full moon days was $5.9: 2 \cdot 3$ (range $2-10$ ) but on new moon days enly $5 \cdot 1 \div 2 \cdot 6(0-12)$.

We made comparisons for each full moon and new moon pair, and found $t=1.8487$, $\mathrm{df}=61$. If we merely ask whether there might be a significant difference among the pairs then $\mathrm{p}=0.07$, which does not reach standards for significance. However, the report from India specified a direction of difference and allowed a prediction, and if we consequently adopt a one-tailed test then $p=0.035$. The likelihood that the higher rate of admissions for poisoning on full moon days than on new moon days in Edinburgh, as in Patna, could be a matter of chance alone would thus be only about 1 in 28 .

IAN OSWALD

IAN M GOLLAND KirSTINE ADAM

\begin{abstract}
Regional Poisoning Treatment Centre,

Royal Infirmary of Edinburgh,

Edinburgh EH3 9 YW
\end{abstract}

\section{Medical equipment for expeditions}

SIR,-While congratulating Dr Robin Illingworth on his excellent article on expedition medical equipment (17 January, p 202), I would like to take issue on a few points. Many of the decisions of what to take are based on personal preference and one's own experience of past expeditions. I am sure, however, that all members of an expedition should carry in their personal medical kit an exposure (survival) bag, costing about $£ 2$, and weighing a few ounces.

In the field kits Dr Illingworth includes "Blood lancets (for blisters and splinters)." I think that this is dangerous advice. Blisters are normally best left untouched as healing is more rapid in the sterile wet conditions of the blister fluid. Where it is not possible to leave the blister intact, they should never be lanced-a sterile wound is converted into an unsterile wound in a marvellous culture medium, and sepsis frequently follows. If the blister must be opened, or if the overlying dead skin is already broken, then it should be deroofed-that is, the dead skin should be completely removed. From my experience this is best done just before crawling into one's sleeping bag, as the wound is nearly dry and painless by the morning. While discussing blisters I would recommend the addition of a roll of $2.5 \mathrm{~cm}$ ( 1 in) Micropore tape to the personal medical kits. If the heel becomes uncomfortable while walking, then a piece of Micropore stuck on will frequently prevent a full-scale blister developing, probably by decreasing the friction over the involved area.

The second important omission in the mobile and base camp kits suggested is an eye pad. If an expedition is carrying amethocaine eye drops, which can be useful for removing foreign bodies, then an eye pad is obligatory, or the resulting problems that could be caused by dust, sand, etc entering the unprotected, anaesthetised eye may be far worse than the original problem. It could be argued that any doctor would of course fashion an eye pad from gauze or whatever, but it must be remembered that most ex- peditions do not have a medical officer, and the presence of an eye pad, with a relevant note on the amethocaine, will act as a reminder.

And then some personal preferences. I would normally put chlorpheniramine tablets in the field kits, especially in arctic and tropical climes, and would also include some tubes of silver sulphadiazine cream (Flamazine) in the base camp kits for use on burns and major grazes.

Finally I would entirely agree that surgery in the field is very much a last resort, but if there was someone suitably qualified, then I would include local anaesthetics in the kit. Not only are they useful for minor surgery, but local infiltration of the fracture site is widely used on the Continent for manipulations, and in Africa I have carried out major abdominal surgery, caesarean sections, etc, with local or regional anaesthesia. I would much prefer it to ketamine if I was on my own.

Department of Plastic Surgery,
St James's University Hospital,
Leeds LS9 7TF

A H N ROBERTS

SIR,-In his interesting article on expedition medicine Dr Robin Illingworth advocated the use of mercurochrome solution to reduce the occurrence of wound infections in the tropics (17 January, p 202). It is preferable to replace this obsolete disinfectant by chlorhexidine (Hibitane) or povidone-iodine (Betadin). One has to bear in mind, however, that polyvinylpyrrholidon iodine complexes will disintegrate in high temperatures. A comparison between chlorhexidine solutions and povidone-iodine after incubation for four weeks at $60^{\circ} \mathrm{C}$ demonstrated that the iodine disinfectant deteriorated completely while the chlorhexidine suffered a loss of less than $1 \%$. Chlorhexidine will therefore be the disinfectant of choice, not only for expeditions in tropical areas but also in first-aid kits in the motorcar. During a trip to Spain this summer the thermometers in the glove compartment and in the boot reached easily temperatures of $60^{\circ} \mathrm{C}$ and more.

G T HANEVELD

3743 HX Baarn, The Netherlands

\section{Mistletoe hepatitis}

SIR,-The interesting paper (17 January, p 186) reporting a case of recurrent hepatitis, proceeds to the conclusion that the hepatotoxic reaction was due to a preparation of mistletoe. In the absence of full authentication of the experimental material, a controlled test, and the exclusion of confounding factors coincidental with ingestion of the tablets, it would appear premature and misleading to adopt as a short title "Mistletoe hepatitis," thereby implying that a novel syndrome has emerged. The hypothesis that mistletoe is "probably the cause of the illness" finds no support in recorded pharmacological studies of Viscum album and requires much firmer evidence than is adduced in this paper.

While a scientist might regard this contribution as unconvincing, a practitioner with experience in the therapeutic use of Viscum album would be incredulous that the aqueous extract from $90 \mathrm{mg}$ mistletoe, less than onetwentieth of the minimum pharmacopoeial dose, could cause hepatitis in a few days.

I believe that the authors have been mis- informed when they state that "mistletoe is one of the ... most widely used herbal remedies." The amount used today is small. Mistletoe is not included in the General Sale List of medicines and is not incorporated in any products subject to licence under the Orders of the Medicines Act.

The caveat of the closing paragraph, extending to the whole range of herbal remedies the conclusions derived from the reaction of a single person to a single product, in my judgment adds nothing to the value of the communication.

F Fletcher Hyde Department of Research,

National Institute of Medical Herbalists Leicester LE8 0GE

\section{"Benign" monoclonal IgE gammopathy}

SIR,-Dr B M Colls (1 November, p 1215) has disputed the statement in our paper (23 August, p 539) that monoclonal gammopathy can be found in about $1 \%$ of the population beyond the age of 25 . As a major argument against it he refers to Hobbs's findings of an $0.8 \%$ incidence of paraproteinaemias in 7220 hospitalised patients, ${ }^{1}$ a figure with which we readily agree. We must expect some variation of incidence rate for paraproteinaemias when studies of different ethnic populations with varying age distributions and varying health status are compared and when diverse detection techniques of paraproteins are applied.

Dr Colls further disputes our statement that "benign" paraproteinaemia of the IgG-, IgA-, and IgM-class or light chain type is only rarely followed by multiple myeloma or Waldenström's macroglobulinaemia; this can easily be answered. In the first report by Axelsson the examination of 39 individuals with benign monoclonal gammopathy five and a half years after the detection of the $\mathrm{M}$-component did not in any case reveal transition into multiple myeloma or Waldenström's disease; however, multiple myeloma was observed in two and lymphona in one of the 27 individuals who could be evaluated after 11 years of observation. ${ }^{2}$ Likewise, in another study ${ }^{3}$ only one out of 15 individuals with benign monoclonal gammopathy developed macroglobulinaemia during a five-year follow-up. These findings and the missing evidence for malignant transformation into plasmocytoma obtained in mice with idiopathic paraproteinaemia (J Radl, personal communication) strongly emphasise our position.

In further support of his statement Dr Colls cites data from a study reported by himself and his associates. ${ }^{4}$ They found 11 paraproteinaemias in 2670 individuals 21 years of age or older. Two patients were considered non-evaluable; of the remaining nine, five presented with malignant conditions (two myelomas, two macroglobulinaemias, one lymphosarcoma and leukaemia) and four were considered to have benign monoclonal gammopathy. Their observation of two myeloma cases in a small collection of 2670 cases can be interpreted only in terms of a highly selective bias in the population studied, since established epedemiological data ${ }^{5}$ show a myeloma incidence rate of $2-4 / 100000$ (the probability of the myeloma incidence rate reported by Colls is less than 0.005 , Poisson's distribution analysis). Furthermore, in that study only four of nine evaluable patients were classified as having benign monoclonal gammopathy, representing a ratio of $4: 5$ for benign versus malignant gammopathies. This strongly contrasts with an incidence of benign monoclonal gammopathies estimated to be 40-100 times higher than that of malignant plasma cells dyscrasias and paraproteinaemia associated with lymphomas or leukaemias. ${ }^{6}$ ?

Finally, we consider it superfluous to 
define the term "benign" paraproteinaemia in a journal addressing itself mainly to internists. This was already dealt with extensively several years ago by Waldenström ${ }^{8}$ and was recently reviewed in detail by Kyle. ${ }^{9}$ It is included in every textbook of haematology and is well known to everyone familiar with internal medicine. However, the various parameters useful in differential diagnosis of benign monoclonal gammopathy and malignant plasma cell dyscrasias might be of interest and can be found in a recent review by Faranghi and Ossermann. ${ }^{10}$ It is also a generally accepted fact that patients with benign monoclonal gammopathy should be clinically examined at regular intervals.

University Department of Medicine II,

H LudwiG

Vienna, Austria

${ }_{2}^{1}$ Hobbs JR. Br Med $\mathcal{F}$ 1967; iii :699-704.

${ }^{3}$ Kyle RA, Finkelstein S, Elveback LR, et al. Blood

$1972 ; 40: 719-24$

Carrell RW, Colls BM, Murray JT. Aust NZ 7 Med

1971 ;iv:398-401.

yle RA. The monoclonal gammopathies. Springfield,

Illinois: Charles C Thomas, 1976.
6 Axelsson U, Hallen J. Br $\mathcal{F}$ Haematol 1968;15:417-20.

7 Radl J. Clin Immun Immunopath 1979;14:251-5.

8 Waldenström J. Acta Med Scand 1964;176:345-65.

$\checkmark$ Kyle RA. Am $\mathcal{F}$ Med 1968;64:814-26.

Faranghi M, Ossermann EF. In: Twomey JJ, Good RA, eds. The immunopathology of lymphoreticular neoplasms. London: Plenum, 1979: 641-718.

\section{Fluid absorption during transurethral resection}

SIR,-Mr D E Osborn and others (6 December, $p$ 1549) have once again focused our attention on the dangers of fluid absorption during the increasing number of transurethral resections that are being performed. We have managed a similar case to their first in a different manner and with a happier outcome.

A 66-year-old man presented in the urology outpatients department at Southmead Hospital, Bristol, with a painless chronic retention, due to benign prostatic hypertrophy. Blood chemistry was normal. He was treated by transurethral resection of his prostate $(15 \mathrm{~g}$ ), isotonic dextrose being used as the irrigant. A spinal anaesthetic was used in conjunction with a light inhalational anaesthetic. Haemostasis was poor and postoperative clot retention necessitated a change of catheter. At this time he was noted to be restless and agitated and he did not settle despite good drainage from the bladder and adequate analgesia. Basal crepitations developed and he went into pulmonary oedema with ventilatory arrest. Endotracheal ventilation was commenced. At this time his serum sodium was noted to be $108 \mathrm{mmol}(\mathrm{mEq}) / \mathrm{l}$, so he was given $250 \mathrm{ml}$ of $20 \%$ mannitol to reduce cerebral oedema and water overload. Peritoneal dialysis was also started, using alternate bags of Dialaflex 61 and 62 in one-hour cycles. Over 12 hours $5150 \mathrm{ml}$ of fluid was drawn off and the patient's sodium was then $123 \mathrm{mmol} / \mathrm{l}$. He was able to breath on his own and respond rationally to questions. His condition improved steadily and he was discharged from hospital on the ninth postoperative day.

We feel that mannitol is the diuretic of choice in fluid overload after transurethral resection as, unlike frusemide, it does not provoke sodium loss. For the severely affected patient peritoneal dialysis, using the regimen described above, is a rapid and effective therapy. Following this experience we measured the serum electrolytes, osmolality, and glucose in 22 patients undergoing transurethral resection of the prostate in our unit. Specimens were taken preoperatively, at the end of the resection, and on the following day, some 18-24 hours after the resection. Isotonic dextrose is used in one theatre and $1.5 \%$ glycine in another unit. The results are presented in the accompanying table.

Serum electrolytes, osmolality, and glucose in 22 patients undergoing transurethral resection of prostate

\begin{tabular}{|c|c|c|c|}
\hline Irrigant & Preoperative & Postoperative & $\begin{array}{c}\text { First } \\
\text { postoperative } \\
\text { day }\end{array}$ \\
\hline $\begin{array}{l}\text { Dextrose } \\
\text { Glycine }\end{array}$ & $\begin{array}{l}\text { Serum sodium }(m n \\
\ldots 136 \cdot 2 \pm 4 \cdot 6 \\
. .140 \cdot 1 \pm 2 \cdot 1\end{array}$ & $\begin{array}{c}\text { mol/l) }(\text { mean }: 1 \\
129 \cdot 0: 9 \cdot 8 \\
139 \cdot 4: 2 \cdot 1\end{array}$ & $\begin{array}{l}I S D) \\
130 \cdot 9+5 \cdot 5\end{array}$ \\
\hline $\begin{array}{l}\text { Dextrose } \\
\text { Glycine }\end{array}$ & 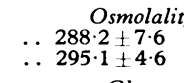 & $\begin{array}{c}\text { ty }(\mathrm{mmol} / \mathrm{l}) \\
286 \cdot 0: 12 \cdot 7 \\
293 \cdot 1: 3 \cdot 7\end{array}$ & $\frac{276 \cdot 2+10 \cdot 5}{-}$ \\
\hline Dextrose & $\begin{array}{r}\text { Glucose } \\
7.9 \pm 3.9\end{array}$ & $\begin{array}{l}(\mathrm{mmol} / \mathrm{l}) \\
19 \cdot 4+15 \cdot 4\end{array}$ & $7 \cdot 8 \pm 2 \cdot 8$ \\
\hline
\end{tabular}

Conversion: SI to traditional units-Sodium: $1 \mathrm{mmol} / \mathrm{l}$ $=1 \mathrm{mEq} / \mathrm{l}$. Osmolality: $1 \mathrm{mmol} / \mathrm{l}=1 \mathrm{mosmol} / 1$. Glucose $1 \mathrm{mmol} / 1 \approx 18 \mathrm{mg} / 100 \mathrm{ml}$

These figures show that when dextrose is used as irrigant there is a significantly greater drop in serum sodium than when glycine is used $(p<0.001)$ but osmolality was not significantly affected. Looking at the individual values we were surprised that some patients had serum sodium levels as low as $104 \mathrm{mmol} / 1$ without clinical signs. By the following morning there was no significant difference in serum sodium compared with the levels before operation; and so it is important to check the value in the immediate postoperative period if the patient's recovery is not as rapid as might be expected or if there is unexplained postoperative confusion. Levels performed routinely the following day will miss these changes.

We also found considerable rises in blood glucose when dextrose was used as an irrigant. One patient's level was as high as $61.8 \mathrm{mmol} / \mathrm{l}$. This also had corrected itself by the following day, but there is a danger that if the sugar is metabolised more rapidly than the water is excreted a hypo-osmolar state may occur.

In summary, we feel that dilutional hyponatraemia is probably an underdiagnosed event following transurethral resection as it may be reasonably well tolerated by a fit patient and will have corrected itself by the following day. It may, however, be a cause of increased postoperative morbidity and even mortality in the patient with inadequate cardiorespiratory reserve. Glycine irrigation causes less electrolyte disturbances than dextrose; but, as has been pointed out, dangerous water absorption can still occur. When water overload does occur mannitol is the drug of choice, with peritoneal dialysis for more extreme cases.

Philip R Allen ROBIN G Hughes

Royal Infirmary,

DAvid J Goldie

Southmead Hospital,

Westbury-on-Trym

Bristol BS10 5 NB

ROBIN H KENNEDY

Frenchay Hospital,

SIR,-I was interested to read the paper by Mr D E Osborn and others (6 December, p 1549) and the letter from Dr G A Rose and colleagues (24 January, p 317).
In a retrospective survey of 372 consecutive patients undergoing prostatectomy, we found lowering of the serum sodium to less than 135 $\mathrm{mmol}(\mathrm{mEq}) / 1$ in $201(54 \%)$. In 56 of these $(15 \%)$ the serum sodium fell to less than 125 $\mathrm{mmol} / \mathrm{l}$, and in these patients clinical evidence of hyponatraemia was apparent. In all cases clinically manifest hyponatraemia was absent within 48 hours of operation and serum sodium levels returned to normal within 72 hours. In a more detailed prospective study, we found evidence of hyponatraemia to be even higher at 12 hours after operation, occurring in 18 of 22 patients studied.

We have attributed this to our policy of forced diuresis rather than glycine absorption, but our experience reinforces the view that hyponatraemia may be a significant though short-lived sequel of transurethral prostatectomy.

R J SHEARER

N J STANDFIELD

St James's Hospital,
London SW12 8HW

\section{Benign familial tremor treated with primidone}

SIR,-Dr M D O'Brien and his colleagues (17 January, p 178) appear to have discovered an important new treatment for benign familial tremor. I note with interest their observation that more patients (about $30 \%$ ) with that condition are intolerant of primidone than has been their clinical experience in patients with epilepsy.

May I suggest an explanation for their observation and a possible remedy for this therapeutic problem? It is probable that many of the patients with epilepsy whom Dr O'Brien and his colleagues have treated with primidone were previously taking other anticonvulsants, while it is unlikely that this was the case in most of the patients with benign familial tremor. It appears that the pronounced toxicity which may result from initial exposure to primidone is related to serum levels of the drug itself rather than its metabolites and it has been shown that prior exposure to phenobarbitone results in tolerance to such effects. ${ }^{1}$

In a study of monotherapy in epilepsy primidone was given to 36 patients. ${ }^{2}$ In 19 patients who were taking other anticonvulsants (phenobarbitone, phenytoin, or carbamazepine) before primidone was commenced there were no severe side effects following the introduction of primidone. In those patients taking phenytoin or carbamazepine plasma levels of derived phenobarbitone rose rapidly and after one week's therapy were similar to the levels usually encountered after three weeks. In contrast, two of the 13 patients in the study who were naive to anticonvulsant therapy were unable to tolerate the initial small doses of primidone $(125 \mathrm{mg})$ because of vertigo and two other patients in this group had nausea and vomiting. In these previously untreated patients plasma levels of derived phenobarbitone rose slowly and were still very low $(<6 \mathrm{mg} / \mathrm{l})$ after one week's treatment with primidone. Levels of phenylethylmalonamide were not measured in either group.

It appears that pending the general availability of phenylethylmalonamide short-term pretreatment with phenobarbitone, or other drugs such as phenytoin and carbamazepine which induce the liver enzymes responsible 